\title{
Um fator de desenvolvimento de clusters no Brasil: a educação profissional
}

\author{
Cluster Development In Brazil: The Professional Education
}

Flávio Henrique dos Santos Foguel*

Miguel Arantes Normanha Filho**

\begin{abstract}
Resumo
O objetivo do artigo é analisar a relevância dos cursos superiores de tecnologia para o sistema de cluster no contexto da realidade brasileira, de forma a demonstrar a importância da formação de tecnólogos (graduação tecnológica) para o desenvolvimento desses aglomerados empresariais. 0 artigo aborda os conceitos de cluster e de educação tecnológica, com uma pesquisa bibliográfica sobre experiências de clusters brasileiros. Nas últimas duas décadas, o conceito de cluster (aglomeração geográfica de empresas interconectadas de segmentos especificos e/ou correlatos) vem ganhando crescente interesse por parte de empresas, governos e estudiosos, em virtude do êxito obtido por várias dessas aglomerações, localizadas em diversas regiões do globo e também no Brasil, em aspectos como competitividade, longevidade, geração de empregos e capacidade de inovação. $O$ artigo também demonstra os esforços do governo brasileiro na definição de suas prioridades, a competitividade exportadora e a substituição de importações, através do plano plurianual (2004-2007), e proporciona uma reflexão sobre como é fundamental melhorar os níveis de educação e capacitação, desenvolver tecnologia, aperfeiçoar as instituições e possibilitar o acesso aos mercados de capitais, demonstrando de forma objetiva a importância da formação de tecnólogos (graduação tecnológica) para o sucesso do sistema de cluster.
\end{abstract}

Palavras-chave: cluster; educação profissional; competitividade.

\begin{abstract}
The aim of this study was to analyze the relevance of technology graduation courses about cluster system on Brazilian reality for demonstrating the technologist formation importance (technologic graduation) to the development of cluster companies. The study deals with cluster and technologic education concepts using a bibliographic research about Brazilian cluster experiences. During the last two decades, the cluster concept (geographical cluster companies interconnected of specific segments and/or related) has provoked a growing interest in companies, government and scholars because of the success of several clusters located in different parts of the globe, as well as in Brazil, on aspects such as competitiveness, longevity, job creation and innovation capacity. The study also reflects the Brazilian government efforts for its priority definition on export and import by Pluriannual Plan (2004-2007), and provides a reflection about the improvement importance of the education and function levels, the technology development, the institutions improvement and a way to make possible the access to the capital market showing the importance of technologist formation (technologic graduation) to the cluster system success.
\end{abstract}

Key words: cluster; competitiveness; professional education.

\footnotetext{
* Mestrando em administração - PUC (SP). Professor na graduação, na pós-graduação e pró-reitor acadêmico adjunto - Centro Universitário Nove de Julho UNINOVE. Endereço : Rua Heitor Peixoto, 725 / 806A, Aclimação, São Paulo - SP - Brasil - CEP 01543-001. E-mail: foguel@uninove.br.

** Mestre em gerontologia social - PUC (SP). Mestre em administração em serviços - Unibero (SP). Professor na graduação,na pós-graduação e coordenador de curso da Faculdade Morumbi Sul. Endereço: Rua João Ramalho 717 / 92 - Perdizes - São Paulo - SP -Brasil - CEP 05008-001. E-mail: mig.arantes@hotmail.com.

Artigo recebido em fevereiro de 2006 e aceito para publicação em setembro de 2006
} 


\section{Introdução}

Desde o final do século XX e em particular nos tempos atuais, o conceito de cluster, aglomeração geográfica de empresas interconectadas de segmentos específicos e/ou correlatos (também definido neste artigo como pólos produtivos e arranjos produtivos locais, entre outras definições) tem chamado a atenção de governos e estudiosos como uma solução para as questões relativas à competitividade das nações em fatores como a geração econômica que vem tendo um forte impacto sobre as oportunidades de emprego, em especial de países em desenvolvimento como o Brasil, muito em função do êxito competitivo obtido por esses arranjos produtivos locais no mercado global.

Os clusters localizados em diversas regiões do Brasil e do mundo têm em comum aspectos como competitividade, longevidade, geração de empregos e capacidade de inovação, entre outras competências diferenciadoras.

O incentivo à existência de clusters, no caso brasileiro, em parte, explica-se pela ineficiência do Estado em estabelecer uma política industrial e tecnológica consistente, seja pelas diversidades regionais e extensão territorial, seja pela falta de recursos, ou ainda pela falta de um planejamento estratégico que considere as reais potencialidades e a competitividade de setores específicos da economia brasileira.

Assim, observamos que dadas às limitações à implementação de política industrial e tecnológica de âmbito nacional, os clusters assumem relevância, pois promovem investimentos, crescimento econômico, aumento de emprego, exportações e desenvolvimento tecnológico.

Entretanto, vale ressaltar que o governo federal vem realizando esforços eficazes no campo da educação, transcendendo as limitações expostas anteriormente e indo ao encontro da vocação, competitividade e sustentabilidade dos arranjos produtivos locais (clusters), de forma a desenvolver tecnologias específicas que atendam às particularidades de tais aglomerados empresariais.

O governo brasileiro, de forma estratégica, definiu a educação tecnológica como um dos quatro eixos estratégicos a serem implementados pelo Ministério da Educação e Cultura a partir de 2005.

A despeito de ser uma estratégia abrangente, a educação tecnológica é obrigatoriamente determinada em função das necessidades do local onde ela será aplicada, em especial, por meio de cursos superiores de tecnologia. Em tal contexto, o objetivo do artigo é o de analisar a relevância dos cursos superiores de tecnologia para o sistema de cluster no contexto da realidade brasileira, de forma a demonstrar a importância da formação de tecnólogos (graduação tecnológica) para o desenvolvimento desses aglomerados empresariais. Situação que preserva o desenvolvimento local, a estrutura social e cultural, o avanço da educação no contexto das necessidades da comunidade, aqui entendida como cluster, e a competitividade dos aglomerados industriais, por terem profissionais com graduação tecnológica compatível e, no local, para atendimento das necessidades de sobrevivência e crescimento dos negócios gerados.

Os currículos dos cursos superiores de tecnologia devem estar em consonância com as Diretrizes Curriculares Nacionais para a Educação Profissional de Nível Tecnológico (BRASIL, 2002) e serem estruturados em função das competências a serem adquiridas; serem elaborados a partir das necessidades oriundas da realidade do trabalho (a aglomeração geográfica de empresas, o cluster) e, por último, capacitarem o estudante, de forma que o mesmo adquira competências que se traduzam na aplicação, desenvolvimento (pesquisa aplicada e inovação tecnológica) e na difusão de tecnologia.

O sucesso das aglomerações geográficas de empresas (clusters) originou-se em um contexto de intensa reestruturação industrial, verificado no âmbito internacional, especialmente nos países desenvolvidos e também em regiões distintas do Brasil com incalculável potencial de crescimento, devido a nossa dimensão territorial e diversidade ambiental e cultural.

O processo de reestruturação industrial foi marcado pelo aprimoramento tecnológico de produtos e processos de produção, em decorrência de inovações baseadas na microeletrônica e na tecnologia de informação (TI). É justamente nela que reside, em parte, o sucesso de um cluster no que tange à relação global, independentemente 
de onde esteja localizado no mundo. Tal relação global é caracterizada pelas transformações das últimas décadas do século XX, a que Castells chama de informacional, global e em rede:

É informacional porque a produtividade e a competitividade de unidades ou agentes nessa economia (sejam empresas, regiões ou nações) dependem basicamente de sua capacidade de gerar, processar e aplicar de forma eficiente a informação baseada em conhecimentos. É global porque as principais atividades produtivas, o consumo e a circulação, assim como seus componentes (capital, trabalho, matéria-prima, administração, informação, tecnologia e mercados) estão organizados em escala global, diretamente, ou mediante uma rede de conexões entre agentes econômicos. É rede porque, as novas condições históricas, a produtividade é gerada, e a concorrência é feita em uma rede global de interação entre redes empresariais. Essa nova economia surgiu no último quarto do século XX porque a revolução da tecnologia da informação forneceu a base material indispensável para sua criação. (CASTELLS, 2002, p.119)

Tais inovações no campo tecnológico de produtos e processos de produção aumentaram a flexibilidade dos processos produtivos, que passaram a atender mais rapidamente às modificações cada vez mais freqüentes da demanda. Segundo Piore e Sabel (1984), essa flexibilidade viabilizou a descentralização da produção, associada a uma elevação da quantidade de recursos, possibilitando assim novas formas de coordenação dos recursos produtivos.

Cabe salientar que os acordos cooperativos entre empresas contribuíram sobremaneira para o aumento da produtividade, aliando concentração de recursos e divisão de custos à geração de inovações. Numa nova ordem mundial, na qual as divisões deixaram de ser ideológicas para serem substituídas por outras de natureza tecnológica (SACHS, 2000), ${ }^{1}$ a competitividade de uma nação depende da capacidade de inovação e desenvolvimento de sua indústria, cenário em que o conceito de cluster ganha importância.

O Plano Plurianual-P.P.A (2004-2007) demonstra a preocupação do governo brasileiro em fomentar o modelo de clusters na economia brasileira. O mesmo documento também deixa clara a preocupação em incentivar e desenvolver o turismo no Brasil.

O desenvolvimento do turismo no Brasil é foco de ações, em face da potencialidade detectada em todo o território nacional, devido à diversidade e exuberância da natureza, dos aglomerados rurais e urbanos localizados em áreas geográficas distintas, possuindo formações arquitetônicas provenientes das influências culturais das diversas etnias que ajudaram na construção da realidade brasileira, seja no contexto de turismo de praia e sol, rural, ecológico, seja no de negócios nos grandes centros urbanos brasileiros e que, de forma genérica, podem ter caracterização de aglomerados territoriais de agentes econômicos, desenvolvendo atividades similares e afins que caracterizem um desenvolvimento empresarial dinâmico. Podemos visualizar isso no trecho que se segue, referente a um dos sete grupos de orientações para elaboração e implementação dos programas e ações do P.P.A.:

A coordenação e o impulso governamental aos investimentos em expansão, modernização e agregação de valor aos bens e serviços nacionais terão como prioridade a competitividade exportadora e a substituição de importações. Buscar-se-á fomentar pólos ou arranjos produtivos locais, fortalecer as grandes empresas nacionais, apoiar as pequenas e médias empresas e atrair investimento direto estrangeiro. A implementação dos investimentos programados, mesmo naqueles setores em que têm longo prazo de maturação, fortalecerá expectativas favoráveis sobre a evolução do balanço de pagamentos, à medida que apontará para a expansão da capacidade de pagamento futuro dos compromissos externos. Por seus efeitos geradores de divisas indispensáveis à redução da vulnerabilidade externa e à sustentação do crescimento, serão enfatizados o turismo, a agricultura, a mineração e as atividades de exportação e produção substitutiva de importações, por meio do adensamento e enobrecimento das cadeias produtivas industriais.

\footnotetext{
${ }^{1}$ Para o autor, uma pequena parte do planeta, responsável por $15 \%$ de sua população, fornece quase todas as inovações tecnológicas existentes.
} 
Não podemos deixar de considerar, no âmbito da análise dos clusters, os benefícios gerados pela educação profissional (em especial, os cursos superiores de tecnologia) que com uma concepção focada nas necessidades oriundas de dado cluster, desenvolve tecnologias e capital humano especializado, gerando inovações e vantagens competitivas.

A educação profissional também potencializa as qualidades locais (geográficas, econômicas ou culturais), resultando no tão desejável desenvolvimento sustentável. Assim, defender o empreendimento de uma política pública para a constituição de cluster é uma forma de diminuir as desigualdades sociais regionais, criando novos e consistentes círculos de desenvolvimento em regiões antes desconsideradas e até "perpetuadas" como improdutivas e carentes e, em tal contexto, a educação profissional, que para efeito deste artigo foca preferencialmente os cursos superiores de tecnologia que proporcionam a viabilidade produtiva das atividades econômicas por meio do saber fazer.

É importante frisar que este artigo não considera cluster como economia de aglomeração, uma vez que observamos no trabalho de Henderson (1999), citado por Galinari et al (2003), que a aglomeração espacial está relacionada à grandeza das economias das indústrias. Porém, a despeito das vantagens obtidas pelas indústrias derivadas da concentração das atividades produtivas, o processo de aglomeração produtiva, ao estimular o crescimento das cidades, pode impor prejuízos à população.

\section{Educação profissional no Brasil}

Manfredi (2002) afirma que as primeiras iniciativas de educação para o trabalho no Brasil datam do período colonial, quando os colégios e as residências dos jesuítas constituíam "escolas-oficina" nos grandes centros urbanos, com o objetivo de formar artesãos, e também pessoas para outros ofícios.

Em 1809, o príncipe regente, futuro D. João VI, cria o Colégio das Fábricas, logo após o fim da proibição de funcionamento de estabelecimentos manufatureiros no Brasil. Já em 1816, foi proposta a criação de uma Escola de Belas-Artes, com o objetivo de articular o ensino das ciências e do desenho direcionando-os para ofícios mecânicos. Ainda na primeira metade do século XIX, foram criadas as casas de Educandos e Artífices em 10 capitais de províncias, visando atender prioritariamente menores abandonados e "reduzir a criminalidade".

Na segunda metade do século XIX, podemos identificar registros de educação profissional com caráter assistencialista para atender aos excluídos socialmente. Vale ressaltar, nesse período, o grande esforço do Estado para organizar a formação profissional, com o foco migrando do atendimento aos necessitados para a preparação de operários para o exercício profissional. Nessa época surgem os liceus de Artes e Ofícios.

A partir de 1906, o ensino profissional passa a ser atribuição do Ministério da Agricultura, Indústria e Comércio, consolidando-se o incentivo ao ensino industrial, comercial e agrícola. Já o ensino comercial foi incentivado com a criação das escolas de comércio, como a Fundação Escola de Comércio Álvares Penteado, em São Paulo.

Em 1937, a Constituição outorgada fala pela primeira vez em escolas vocacionais e pré-vocacionais como um dever do Estado em relação aos menos favorecidos, que deveria ser cumprido em parceria com as indústrias e "classes produtoras" (sindicatos). Juntos, deveriam criar escolas de aprendizes destinadas aos filhos dos operários e de seus associados.

Na década de 1940, são decretadas as leis orgânicas da Educação Nacional, tratando dos diversos níveis do ensino (cabendo destaque ao ensino comercial e ao ensino agrícola). Surgem também nessa década o Senai, o Senac e as escolas técnicas. No conjunto das leis orgânicas, ficava claro que o objetivo do ensino secundário e normal era formar as elites condutoras do país e que o objetivo do ensino profissional era oferecer formação adequada àqueles que necessitavam ingressar precocemente no mercado de trabalho. Somente na década de 1950 permitiu-se a equivalência entre os estudos acadêmicos tradicionais e profissionalizantes (Lei Federal $\mathrm{n}^{\mathrm{o}}$ 1.076/50). Contudo, a plena equivalência entre todos os cursos do mesmo nível, sem a necessidade de exames e provas de conhecimentos, só ocorreu efetivamente com o advento da primeira Lei de Diretrizes e Bases da Educação Nacional (Lei Federal no 4.024/61). 
Na década de 1970, identificamos a generalização da profissionalização no ensino médio, gerando alguns efeitos nefastos, tais como a criação de inúmeros cursos sem investimentos apropriados e perdidos dentro de um segundo grau único, a redução inadequada da carga horária destinada à formação de base e o desmantelamento da rede pública de ensino técnico existente. Já em 1982, esses efeitos são atenuados com a não-obrigatoriedade da profissionalização do segundo grau (Lei Federal no 7.044/82).

Com a Constituição Federal de 1988, o entendimento sobre a educação profissional é reformulado para a ótica dos direitos universais à educação e ao trabalho, que culmina com a Lei de Diretrizes e Bases da Educação (Lei Federal no 9.394/96), a qual entende que:

[...] a educação profissional, integrada às diferentes formas de educação, ao trabalho, à ciência e à tecnologia, conduz ao permanente desenvolvimento de aptidões para a vida produtiva.

\section{A estrutura atual da educação profissional, tecnológica no Brasil}

O Decreto $\mathrm{n}^{\mathrm{0}} 5.154$, de 2004, estabelece que a educação profissional seja desenvolvida por meio de cursos e programas de:

- formação inicial e continuada de trabalhadores;

- educação profissional técnica de ensino médio; e

- educação profissional tecnológica de graduação e pós-graduação.

Estabelece ainda como premissas básicas a serem seguidas:

- organização por áreas profissionais, em função da estrutura sócio-ocupacional e tecnológica; e

- articulação de esforços das áreas de educação, do trabalho e emprego e da ciência e tecnologia.

A oferta dos cursos técnicos e tecnológicos ocorre por meio da rede pública (federal, estadual, do Distrito Federal e municipal) e da rede privada de ensino.

A rede pública federal é composta por uma Universidade Tecnológica, pelos centros federais de Educação Tecnológica (Cefets), pelas escolas técnicas federais, escolas agrotécnicas federais e escolas e colégios técnicos vinculados a instituições federais. Nas esferas estadual e municipal, a oferta é realizada por centros de Educação Tecnológica e por escolas técnicas vinculadas a instituições estaduais ou municipais de ensino.

Já na rede privada, a oferta dos cursos técnicos e tecnológicos acontece por intermédio de universidades, centros universitários, centros de educação tecnológica, faculdades de tecnologia, faculdades integradas ou isoladas, institutos, escolas superiores e escolas técnicas. Integra também a rede privada o Sistema $S$ (Senai - Serviço Nacional de Aprendizagem Industrial, Sesi - Serviço Social da Indústria, Senac - Serviço Nacional de Aprendizagem Comercial, Sesc - Serviço Social do Comércio, Senar - Serviço Nacional de Aprendizagem Agrícola, Senat - Serviço Nacional de Aprendizagem do Transporte, Sest - Serviço Social do Transporte, Sebrae - Serviço Brasileiro de Apoio a Micro e Pequenas Empresas e Sescoop - Serviço Social de Cooperativas de Prestação de Serviços).

\section{A educação profissional tecnológica}

O artigo 10 do Decreto $\mathrm{n}^{\circ}$ 2.208/97 define que:

[...] os cursos de nível superior, correspondentes à educação profissional de nível tecnológico, deverão ser estruturados para atender aos diversos setores da economia, abrangendo áreas especializadas, e conferirão diploma de Tecnólogo.

Os cursos de educação profissional de nível tecnológico serão designados como cursos superiores de tecnologia e deverão (BRASIL, 2001): 
- incentivar o desenvolvimento da capacidade empreendedora e da compreensão do processo tecnológico, em suas causas e efeitos;

- incentivar a produção e a inovação científico-tecnológica, e suas respectivas aplicações no mundo do trabalho;

- desenvolver competências profissionais tecnológicas, gerais e específicas, para a gestão de processos e a produção de bens e serviços;

- propiciar a compreensão e a avaliação dos impactos sociais, econômicos e ambientais resultantes da produção, gestão e incorporação de novas tecnologias;

- promover a capacidade de continuar aprendendo e de acompanhar as mudanças nas condições de trabalho, bem como propiciar o prosseguimento de estudos em cursos de pós-graduação;

- adotar a flexibilidade, a interdisciplinaridade, a contextualização e a atualização permanente dos cursos e seus currículos; $\mathrm{e}$

- garantir a identidade do perfil profissional de conclusão de curso e da respectiva organização curricular.

Atualmente, temos 20 áreas profissionais especializadas na oferta de cursos superiores de tecnologia, com carga horária variando entre 1.600 e 2.400 horas (dois a três anos de duração, dependendo da área profissional do curso). São consideradas áreas para a educação tecnológica: agropecuária, artes, comércio, comunicação, construção civil, design, geomática, gestão, imagem pessoal, indústria, informática, lazer e desenvolvimento social, meio ambiente, mineração, química, recursos pesqueiros, saúde, telecomunicações, transportes e turismo e hospitalidade (BRASIL, 2001).

A educação profissional de nível tecnológico tem como objetivo principal garantir aos cidadãos o direito à aquisição de competências profissionais que os tornem aptos à inserção em setores profissionais nos quais haja utilização de tecnologias. Entende-se por competência profissional a capacidade pessoal de mobilizar, articular e colocar em ação conhecimentos, habilidades, atitudes e valores necessários para o desempenho eficiente e eficaz de atividades requeridas pela natureza do trabalho e pelo desenvolvimento tecnológico. Entretanto, cabe salientar que o desenvolvimento tecnológico deve ser analisado no contexto de cada cluster, levando-nos a refletir e analisar qual técnica seria relevante para uma dada capacidade produtiva e rentável. Assim, o contexto de cada cluster aqui é entendido também como comunidade, pois o local é fator determinante de tal relevância e do significado e ressignificado de técnica para dada ação produtiva, não apenas a utilização de uma sofisticada tecnologia de um país de primeiro mundo, ou a aplicação de uma tecnologia de outro cluster localizado em outra região brasileira. Portanto, a eficácia da educação profissional de nível tecnológico reside na adequação curricular oriunda da necessidade e especificidade local, ou seja, do cluster. O Sebrae (2003) aborda de forma complementar que:

Os arranjos produtivos não são iguais, porque a realidade não é uniforme e a organização da produção é muito diversa. Portanto, cada arranjo conceberá um modelo próprio de desenvolvimento, não obstante seja imprescindivel sempre considerar: as redes locais; as potencialidades, vocações e oportunidades; as vantagens comparativas e competitivas [...] a infra-estrutura existente; o capital humano [...]. (SEBRAE, 2003, p.6)

\section{$E A D$ - ensino a distância}

Outra modalidade de ensino complementar à educação tecnológica, já no nível de pós-graduação, que se insere no contexto das necessidades de um cluster, é o EAD (ensino a distância) que o Senac (2006, p.1) define como:

[...] uma modalidade educativa organizada e sistematizada, onde o participante não estando fisicamente presente em um ambiente formal de ensino-aprendizagem, tem oportunidade de construir conhecimento através da reflexão e da vivência de situações de experiência.

Tal modalidade de ensino é eficaz para um cluster, pois proporciona ensino de alta qualidade vencendo a distância física, com a vantagem de estar acompanhando sempre os avanços e recursos tecnológicos e de comuni- 
cação, que de alguma forma já estão presentes em aglomeração geográfica de empresas interconectadas de segmentos específicos e/ou correlatos por necessidades oriundas de suas atividades de negócios. Segundo Mo$\operatorname{ran}(2006)$ :

Na medida em que avançam as tecnologias de comunicação virtual (que conectam pessoas que estão distantes fisicamente, como a Internet, telecomunicações, videoconferência, redes de alta velocidade), o conceito de presencialidade também se altera. Poderemos ter professores externos compartilhando determinadas aulas, um professor de fora "entrando" com sua imagem e voz na aula de outro professor... Haverá, assim, um intercâmbio maior de saberes, possibilitando que cada professor colabore, com seus conhecimentos específicos, no processo de construção do conhecimento, muitas vezes à distância.

\section{Cluster}

Para efeito deste artigo, usaremos o termo cluster e outros abordados como sinônimos; porém, cabe ressaltar a observação de Santos (2003):

No Brasil, a experiência recente tem evidenciado, tanto no âmbito do debate acadêmico quanto da formulação de políticas públicas e de iniciativas empresariais, uma grande difusão de estudos e proposições baseadas na abordagem dos chamados clusters produtivos. Na verdade, constata-se que a grande maioria dos casos de idéia de aglomeração de empresas pouco tem a ver propriamente com o conceito de cluster produtivo, constituindo-se, em meros agrupamentos de firmas, unidas por nexos muito frágeis e interesses difusos. A idéia de cluster produtivo envolve uma série de características e condicionalidades que extrapolam em muito a conotação que usualmente vem se difundindo no Brasil. (SANTOS, 2003, p.1)

A abordagem sobre cluster não é tão recente. Porter (1999), um dos grandes estudiosos atuais do assunto, afirma que Marshall (final do século XIX) abordou as localidades industriais especializadas em seu livro Princípios de economia. Diz ainda que Weber, no final da década de 1920, e Lösch, na década de 1950, também abordaram o tema. A partir da década de 1970, a produção de literatura a respeito torna-se abundante.

A Federação das Indústrias de Minas Gerais define cluster como:

[...] um conjunto de empresas e entidades que interagem, gerando e capturando sinergias, com potencial de atingir o crescimento competitivo contínuo superior ao de uma simples aglomeração econômica. Nele, as empresas estão geograficamente próximas e pertencem à cadeia de valor de um setor industrial. Essa interação das empresas gera, entre outros benefícios, redução de custos operacionais e dos riscos apresentados, aumento da qualidade dos produtos e serviços, acesso à mão-de-obra mais qualificada, atração de capital, criação de empreendedores e melhor qualidade de vida (FEDERAÇÃO DAS INDÚSTRIAS DE MINAS GERAIS, 2000).

Já a Federação das Indústrias do Estado de São Paulo (Fiesp), não faz o uso da expressão cluster, e adota "ação regional: arranjo produtivo local" (APL), assim definido:

[...] é o termo que se usa para definir uma aglomeração de empresas com a mesma especialização produtiva e que se localiza em um mesmo espaço geográfico. Os APLs mantêm vínculos de articulação, interação, cooperação e aprendizagem entre si, contando também com apoio de instituições locais como Governo, associações empresariais, instituições de crédito, ensino e pesquisa (IEL, 2006).

Como exemplo, podemos citar a cidade de Mirassol, no interior de São Paulo, com vocação moveleira, que é designada pela Fiesp (2005) como Arranjo Produtivo Local de Mirassol - Móveis. Para que possamos verificar os resultados do Arranjo Produtivo Local (APL) de Mirassol, com base nos dados da Fiesp (2005), as empresas do APL obtiveram ganho de produtividade de $13,4 \%$, descontado o efeito inflação. No que tange às exportações, 14 indústrias montaram um consórcio de exportação e outras cinco indústrias uniram-se para custear a 
viagem de um representante comum para a África e Europa, onde foi feita a divulgação de mostruário e prospecção de clientes. Cabe ressaltar que as empresas adotaram compras cooperadas.

A Fiesp destaca no APL de Mirassol, um importante fator medido, que foi o aumento da relação entre receita e custos de materiais de $2,7 \%$, explicado pela redução do desperdício de materiais ou pelo aumento na venda de produtos com maior valor agregado.

Em 7 de novembro de 2007 foi realizado na capital de São Paulo, na sede da Fiesp, o "I Encontro de arranjos produtivos do estado de São Paulo", cujo objetivo foi o de divulgar os benefícios do projeto APLS, que a entidade desenvolve em vários pólos produtivos paulistas em parceria com o Sebrae-SP.

O projeto APLS atinge indiretamente 800 indústrias e 17.000 empregos, sendo atendidas, de forma direta, 200 indústrias, micro, pequenas e médias nos seguintes pólos industriais do interior de São Paulo: Vargem Grande do Sul: cerâmica estrutural; São José do Rio Preto: jóias; Mirassol: móveis; Ibitinga: cama, mesa, banho e bordados; Limeira: bijuterias; Itu: cerâmica estrutural; Tambaú: cerâmica estrutural e Tatuí: cerâmica estrutural.

Piore e Sabel (1984) produzem um trabalho no qual se abordou, pela primeira vez, a noção de especialização flexível como estratégia competitiva para que as empresas se adaptassem às rápidas mudanças com as quais os agentes econômicos passaram a se defrontar.

Altenburg e Meyer-Stamer (1999) definem cluster como uma aglomeração significativa de empresas em uma área especialmente delimitada que possui uma clara especialização produtiva, com um eficaz comércio entre elas.

Para Porter (1998), clusters são concentrações geográficas de empresas interconectadas de determinado setor de atividade e companhia correlatas, vinculadas por elementos comuns, sendo o seu todo maior do que a soma das partes. Eles se expandem diretamente em direção aos canais de distribuição e aos clientes e, lateralmente, em direção aos fabricantes de produtos complementares e empresas de setores afins.

O conceito de cluster pode englobar também universidades, institutos de pesquisa, organizações nãogovernamentais e entidades comerciais que proporcionam treinamento, informação, estudos e apoio técnicos aos integrantes do aglomerado. Na análise ampliada de Porter (1998) é que podemos situar a existência do curso superior de tecnologia.

É importante o observado por Hissa (2003), que o tipo de desenvolvimento observado nos clusters é conhecido tanto na literatura econômica quanto entre sociólogos, geógrafos e antropólogos como a "teoria do desenvolvimento local":

[...] um modelo de desenvolvimento que não se baseia simplesmente nas variáveis econômicas como taxas de juros, salários, inflação, déficit público, câmbio etc., mas sim nas potencialidades de uma determinada região geográfica delimitada, levando-se em consideração, principalmente, os recursos naturais existentes, a vocação trabalhista e produtiva da comunidade e fatores socioculturais como: laços familiares, confiança entre agentes produtores, grau de relacionamento entre as empresas, cooperação interfirmas, costumes, tradições, religião, etnia, laços culturais [...]. (HISSA, 2003, p.1)

Em tal contexto, verificamos que a grade curricular para o curso superior de tecnologia deverá, no que tange ao perfil do profissional quanto a sua capacidade empreendedora, atender às necessidades do local, pois deverá ser "especializado em segmentos (modalidades) de uma determinada área profissional" para as necessidades do cluster, além do que se torna de fundamental importância a consideração dos fatores socioculturais para uma perfeita adequação curricular.

\section{Objetivo do cluster}

O objetivo de um cluster é o ganho de eficiência coletiva, estabelecendo vantagem competitiva baseada na ação conjunta e em economias externas locais. Concentrações geográfica e setorial são sinais evidentes da formação 
de um cluster, porém não suficientes para gerar a eficiência coletiva. Para Amato Neto (2000), o conceito de eficiência coletiva é representado por um conjunto de fatores facilitadores. São eles:

- divisão do trabalho e da especialização entre produtores;

- estipulação da especialidade de cada produtor;

- surgimento de fornecedores de matéria-prima e de máquinas;

- surgimento de agentes que vendam para mercados distantes;

- surgimento de empresas especialistas em serviços tecnológicos, financeiros e contábeis;

- surgimento de uma classe de trabalhadores assalariados com qualificações e habilidades específicas; e o

- surgimento de associações para a realização de lobby e de tarefas específicas para o conjunto de seus membros.

Os fatores facilitadores demonstram a relevância dos cursos superiores de tecnologia, pois os formandos terão formação específica voltada para aplicação, desenvolvimento - pesquisa aplicada e inovação tecnológica - e a difusão de tecnologias; gestão de processos de produção de bens e serviços e capacidade empreendedora, conforme exposto nas Diretrizes Curriculares Nacionais para a Educação Profissional de Nível Tecnológico.

\section{A influência dos clusters sobre a competição}

Para Porter (1998), a concorrência moderna depende da produtividade, que por sua vez depende do modo como as empresas concorrem, e não dos campos em que concorrem. Empresas podem ser altamente produtivas em qualquer setor se utilizarem métodos avançados aliados à tecnologia, ofertando produtos e serviços sofisticados. Entretanto, essas variáveis são altamente influenciadas pelas condições do ambiente empresarial local.

Para Porter (1998), os clusters afetam a capacidade de competição de três maneiras principais:

- AUMENTANDO A PRODUTIVIDADE DE EMPRESAS SEDIADAS NA REGIÃO: a participação em um cluster possibilita que as empresas sejam mais produtivas na aquisição de insumos, na contratação de mão-de-obra, no acesso a tecnologias, informações e instituições, no nível de coordenação com indústrias complementares e na melhora de fatores de medição e motivação. As empresas participantes de um cluster podem utilizar um pool de profissionais experientes e especializados, reduzindo custos de recrutamento. Os clusters tendem a se tornar atraentes para pessoas talentosas, devido às oportunidades que oferecem. Já a aquisição de insumos é mais eficiente, pois há uma base sólida e especializada de fornecedores. Os custos totais das transações são reduzidos, devido à aquisição de insumos no local. Como a comunicação com os fornecedores é melhor, estes podem proporcionar serviços auxiliares ou de apoio para os integrantes do cluster. Quanto à informação, podemos afirmar que os clusters acumulam grande quantidade de informações diversificadas, com acesso preferencial aos seus integrantes. A complementação entre os membros do cluster pode fazer com que o bom desempenho de um aumente o êxito dos demais. A quantidade e intensidade das interconexões empresariais fazem com que o cluster como um todo seja maior que a simples soma de seus integrantes. Além de todas essas questões, a concorrência local é altamente motivadora dentro de um cluster, mesmo entre empresas não-concorrentes ou concorrentes indiretas. Como os concorrentes locais compartilham as mesmas variáveis e executam atividades semelhantes, a medição e comparação de desempenho ficam mais fáceis.

- INDICANDO A DIREÇÃO E O RITMO DA INOVAÇÃO QUE SUSTENTAM O FUTURO CRESCIMENTO DA PRODUTIVIDADE: o papel dos clusters na capacidade de inovação contínua das empresas é vital. Consumidores exigentes que fazem parte do cluster propiciam às empresas participantes uma vitrine mais adequada para o mercado do que os seus concorrentes isolados. O relacionamento permanente e a proximidade entre os membros do cluster possibilitam que estes tenham com antecedência informações estratégicas, como em relação à evolução tecnológica do setor, por exemplo. Como vários fornecedores fazem parte do cluster, as empresas podem adquirir com rapidez tudo o que precisam para a implementação das inovações. 


\section{- ESTIMULANDO A FORMAÇÃO DE NOVAS EMPRESAS, O QUE EXPANDE E REFORÇA O PRÓ-}

PRIO CLUSTER: novos fornecedores surgem em um cluster porque a base concentrada de clientes diminui seus riscos e facilita a descoberta de oportunidades de mercado. Participantes de um cluster tendem a perceber mais rapidamente as lacunas em produtos e serviços, o que é um excelente motivo para iniciar um novo negócio. As barreiras de entrada no mercado também tendem a ser menores do que em outras regiões e o custo de capital acaba sendo menor, pois as instituições financeiras e investidores locais já estão mais familiarizados com o cluster.

Já o Sebrae (2003), no que tange ao APL (arranjo produtivo local), considera como dimensões da competitividade e níveis de atuação, três dimensões (competitivas), como meio de formular estratégias de atuação e de definição de ações: 1) dimensão empresarial - fatores ou condicionantes de domínio das empresas; 2) dimensão estrutural - fatores ou condicionantes relacionados ao mercado e à tecnologia (acesso), à configuração da indústria e à dinâmica específica da concorrência; 3) dimensão sistêmica - fatores macroeconômicos, internacionais (mercado internacional), avanço do conhecimento, infra-estruturais, fiscais, financeiros e políticoinstitucional (SEBRAE, 2003, p.19-20).

\section{O ciclo de vida de um cluster}

Para Porter (1999), um cluster normalmente tem raízes históricas, podendo também surgir de necessidades locais específicas. A existência anterior de setores de fornecedores, setores afins ou mesmo de clusters inteiros relacionados pode ser o impulso inicial para o nascimento de novos clusters. Estes também podem surgir de uma ou duas empresas inovadoras que estimulem a formação de outras.

O cluster de Rio Verde (GO) é um bom exemplo desse último caso. Aproveitando a grande disponibilidade de grãos (milho e soja) entre outros fatores, a Perdigão implantou em Rio Verde o projeto Buritis, um complexo agroindustrial de $100.000 \mathrm{~m}^{2}$ para a produção de carne de frango e suínos. Em seguida, uma série de outras empresas correlatas e prestadoras de serviços foi atraída para a região. No início, vieram fábricas de embalagens, frigoríficos, fornecedores de insumos, adubos, sementes, máquinas agrícolas e empresas de transporte. Em seguida, chegaram os serviços de apoio, como hotéis, restaurantes, supermercados e revendedoras. Programas educacionais ligados à atividade começaram a ser disponibilizados na região, destacando-se a granja-escola e o Centro Tecnológico Comigo (SOUZA, 2003).

Um cluster em crescimento sinaliza oportunidades e seu sucesso atrai novos talentos. À medida que chegam fornecedores especializados, informações são acumuladas e pesquisas são desenvolvidas, a visibilidade e a força do cluster aumentam. Num próximo estágio, o cluster amplia-se, buscando englobar os setores relacionados. A evolução dos clusters é contínua, à proporção que as instituições locais desenvolvem-se e modificam-se.

Já a decadência de um cluster pode ocorrer devido a descontinuidades tecnológicas, fato que pode neutralizar muitas vantagens simultaneamente. Nesse caso, os recursos do cluster tendem a se tornarem irrelevantes. A inflexibilidade interna às ameaças externas também é um ponto de vulnerabilidade para os clusters. Excessos de fusões, postura cartelista e endurecimento de regras sindicais são alguns exemplos dessas inflexibilidades internas.

Para que possamos evitar a decadência de um cluster em um cenário em que o fator de tecnologia é fundamental, devemos ter atenção com a educação profissional tecnológica de graduação articulada com pós-graduação. Isso significa ter uma articulação de forma mais abrangente, que envolva esforços integrados das áreas de educação, do trabalho, da ciência e tecnologia. 


\section{O modelo diamante de competitividade}

Para Porter (1999), o cluster é uma derivação do modelo diamante, sendo mais bem visto como uma manifestação da interação entre suas quatro determinantes. Os componentes do modelo são:

- condições de fatores: dizem respeito aos fatores de produção, tais como recursos humanos qualificados, recursos físicos, recursos de conhecimento, recursos de capital e infra-estrutura necessários para competir em um determinado setor;

- condições de demanda: dizem respeito à natureza da demanda do mercado local para os bens e serviços do setor. A demanda interna determina o rumo da inovação pelas empresas do país;

- setores correlatos ou de apoio: são aqueles nas quais as empresas, ao competirem, podem coordenar ou compartilhar atividades na cadeia de valor ou, ainda, aqueles que envolvem produtos complementares; e

- estratégia, estrutura e rivalidade das empresas: apontam as circunstâncias nacionais e o contexto nos quais as organizações são criadas, organizadas e dirigidas, bem como a natureza da rivalidade interna.

$\mathrm{O}$ autor afirma também que o modelo diamante afeta a competição de três maneiras:

- pelo aumento da produtividade das empresas ou indústrias constituintes;

- pela ampliação da capacidade de inovação; e

- pelo estímulo a novos negócios que sustentam a inovação e expandem o cluster.

Ao analisarmos o modelo diamante e a maneira como o mesmo afeta a competição, identificamos as instituições ofertantes de cursos superiores de tecnologia inseridas em setores correlatos ou de apoio e com fortíssima influência sobre as condições dos fatores, gerando recursos humanos qualificados e melhorando os recursos de conhecimento dos clusters. No caso do APL (arranjo produtivo local), vamos verificar o fortalecimento da dinâmica do APL, que é o "componente I" do seu processo de desenvolvimento, no qual se observa em tal estágio a identificação e relação com os cursos superiores de tecnologia, pois tal componente traduz:

O conjunto das ações de articulação, sensibilização e mobilização visa desencadear o processo de envolvimento e aproximação entre os atores locais e a construção de políticas de relacionamento [...] As ações desse componente podem ser agrupadas em três dimensões: (a) governança; (b) identidade territorial; e (c) interação e cooperação. (SEBRAE, 2003, p.25)

Os cursos superiores de tecnologia, no que tange à formação daqueles que irão trabalhar nos clusters, estarão capacitados para tal, pois os currículos serão estruturados em função das competências a serem adquiridas e a partir das necessidades do mundo do trabalho. Capacita o estudante de modo que este adquira competências que se traduzam na aplicação, desenvolvimentos e difusão de tecnologia, bem como na gestão de processos de produção de bens e serviços e no estímulo a uma postura laboral.

A figura 1 apresenta os determinantes da vantagem competitiva nacional, os quais representam o modelo diamante de Porter. 


\section{Figura 1}

\section{Modelo diamante}

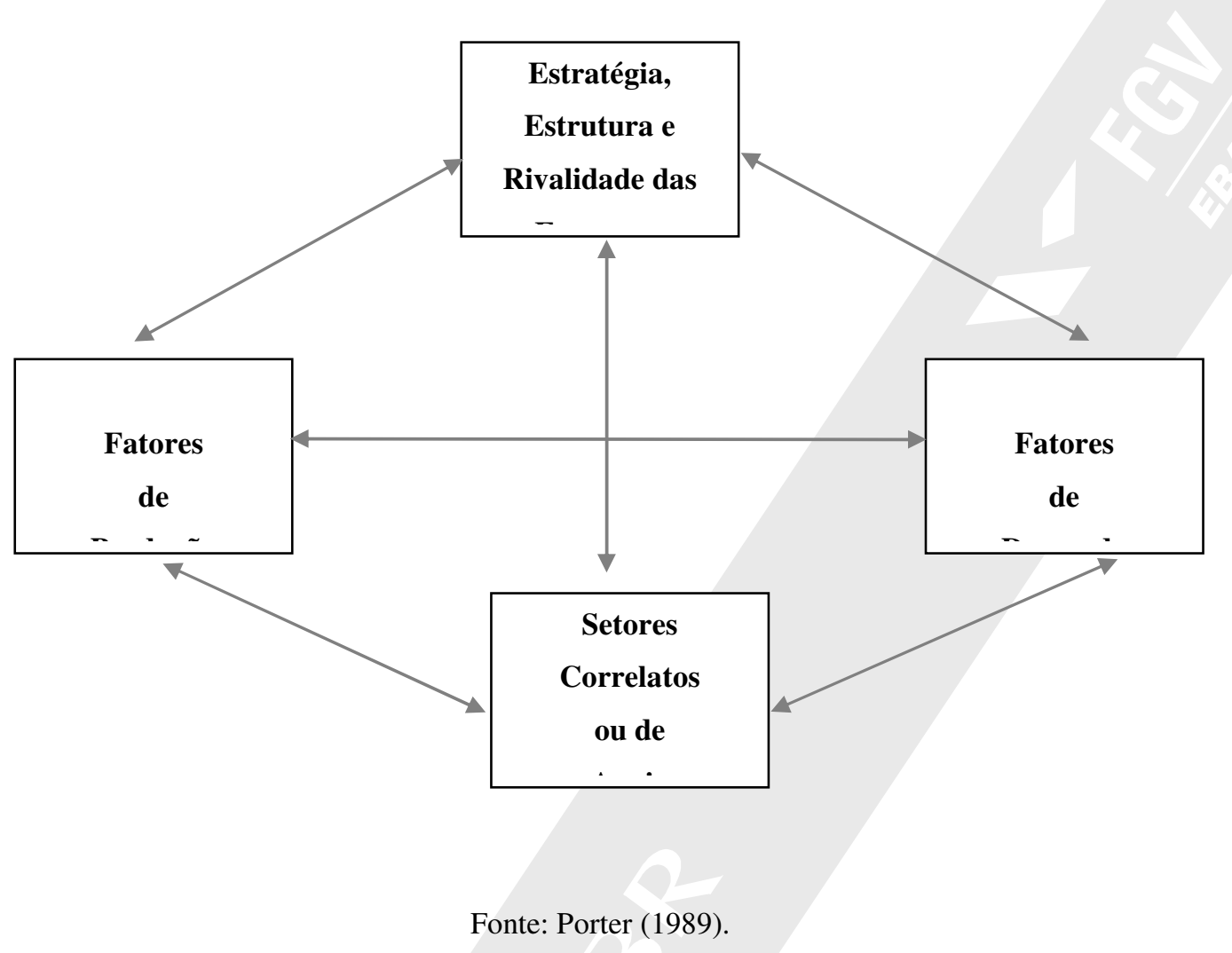

Porter enfatiza também o papel do governo, como influenciador da competitividade internacional de uma nação, pois as ações governamentais podem melhorar ou piorar a vantagem competitiva de uma nação. O governo influencia e é influenciado pelos quatro determinantes do modelo diamante.

$\mathrm{O}$ modelo diamante deve ser entendido como um sistema, em que cada um dos determinantes influencia e depende do estado do outro. $\mathrm{O}$ efeito sistêmico exercido pelo modelo cria um contexto que possibilita a existência dos aglomerados de indústrias competitivas.

\section{Clusters no Brasil}

No Brasil, podemos identificar vários clusters de sucesso, alguns deles já fortemente consolidados. São exemplos dignos de nota o cluster de tecnologia aeronáutica, em São José dos Campos (SP), o de cristais em Santa Catarina, o automobilístico no ABC paulista, o de grãos, aves e suínos em Rio Verde (GO), o de calçados em Novo Hamburgo (RS), o de semijóias em Limeira (SP), o de cama, mesa e banho em Santa Catarina, o de turismo na região do Sauípe (BA) e o de fruticultura no Vale do São Francisco (Petrolina, PE, e Juazeiro, BA) (LIMA, 2003). Deve-se notar a presença e a importante contribuição de cursos superiores de tecnologia nesses clusters, ofertados por meio de faculdades de tecnologia estaduais, centros federais de educação tecnológica e instituições privadas de ensino superior.

O cluster situado no Vale do Rio São Francisco, na divisa entre os estados de Pernambuco e Bahia, em torno das cidades de Petrolina (PE) e Juazeiro (BA), é o maior pólo exportador de frutas do Brasil, faturando US\$90 milhões no mercado externo. Em 2002, 93\% da uva e 90\% da manga exportada pelo Brasil saíram de lá. É interessante dizer que o atual sucesso nasceu do corte da ajuda federal. A região recebia subsídios desde 1948 e começou a vê-los rarear a partir de 1990. Foi então que os empresários e lideranças políticas locais resolveram investir os próprios recursos, aproveitando a infra-estrutura de irrigação construída pelo governo. Realizaram, 
então, o mapeamento dos períodos de entressafra do hemisfério norte. Com auxílio do Sebrae e da Embrapa (Empresa Brasileira de Pesquisa Agropecuária) desenvolveram tecnologia para induzir a floração e passaram a concentrar as colheitas nesses períodos.

O Centro Federal de Educação Tecnológica de Pernambuco (Cefet-PE) está presente em Petrolina oferecendo vários cursos técnicos e três cursos superiores de tecnologia relacionados à vocação do cluster: tecnologia em alimentos de origem vegetal, tecnologia em fruticultura irrigada e tecnologia em viticultura e enologia. O Senai também está presente na região por meio de seu Centro Regional de Tecnologia em Alimentos (Certa), oferecendo cursos técnicos na área de alimentos.

É importante ressaltar que não basta formar profissionais para atender às necessidades da realidade local, a fruticultura, mas também oferecer cursos relacionados a outras atividades de apoio, tais como: logística empresarial, em face da complexa cadeia que se estabelece para deslocar as frutas do sertão nordestino brasileiro para um dado país do Mercado Comum Europeu; de marketing internacional, pois múltiplos países que compram as frutas o fazem em épocas distintas e possuem características culturais e hábitos de compra e consumo diferenciados; de gestão empresarial, com características específicas e sofisticadas; de produção, não somente a relativa ao campo, que já é sofisticada e diferenciada por usar a tecnologia de canais irrigados (experiência pioneira em irrigação em áreas de seca no Brasil); até o processo final de limpeza, normas sanitárias, impacto ambiental e de embalagens, com equipamentos específicos e de última geração; de administração financeira; de gestão de custos e orçamento.

Assim, podemos verificar que um cluster, por meio da identificação principal do produto ou do serviço que o caracteriza, necessita de capacitações diferentes e em muitos casos, únicas, as quais deverão ser desenvolvidas com ênfase no saber fazer, gerando não somente profissionais especializados, mas também experimentos e publicações científicas no campo acadêmico que poderão ser compartilhados com outros arranjos produtivos locais.

Segundo Bacal (2001), o Instituto Brasileiro de Geografia e Estatística (IBGE) realizou estudos por meio de seu Cadastro Empresarial (Cempre), demonstrando que as regiões brasileiras estão se especializando industrialmente. As indústrias brasileiras concentram-se por categorias de uso e aproximam-se em busca de economia e competitividade. Esses estudos demonstram a seguinte situação:

- região Norte: produção de bens duráveis e semiduráveis;

- região Nordeste: produção de bens intermediários e surgimento de bens semiduráveis;

- região Centro-Oeste: produção de bens não-duráveis;

- região Sudeste: produção de bens intermediários e não-duráveis; e a

- região Sul: produção de bens de capital e não-duráveis.

Para Porter (1999), o desenvolvimento de clusters eficientes é vital para que países pobres e em desenvolvimento ultrapassem a etapa de meros fornecedores de mão-de-obra barata e recursos naturais para o mercado mundial. Para isso, é fundamental melhorar os níveis de educação e capacitação, desenvolver tecnologia, aperfeiçoar as instituições e possibilitar o acesso aos mercados de capitais.

\section{Considerações finais}

No atual contexto competitivo, o modelo baseado em cluster, também entendido no artigo como arranjo produtivo local (APL), é altamente recomendável para o fortalecimento de segmentos da economia de países em desenvolvimento. Assim, podemos considerar como pressuposto que a competitividade e ampliação do ciclo de vida de tais aglomerados - aglomeração geográfica de empresas interconectadas de segmentos específicos e/ou correlatos - dependem de educação profissional contextualizada e os cursos superiores de tecnologia proporcionam a viabilidade produtiva das atividades econômicas, como também a inovação por meio do saber fazer, além do ser, através da postura cidadã, ética e responsável socialmente, uma vez que a criação e reconhecimento de tais cursos pelo MEC somente se viabiliza em tal dimensão (a do ser). 
O Plano Plurianual (2004-2007) do governo brasileiro deixa clara a decisão de respeitar as características regionais, buscando fomentar e desenvolver o conceito de cluster em nosso país.

Cabe ressaltar que, dentro da abordagem sistêmica do modelo diamante, os investimentos em educação, pesquisa, tecnologia e infra-estrutura são fundamentais para o sucesso dos clusters. A vantagem competitiva está diretamente ligada à capacidade constante de inovação. Tais investimentos gerariam fatores de produção adiantados e especializados, vitais para o processo de inovação. Além disso, fortaleceriam as empresas e os clusters, aumentando a rivalidade local, o que também é muito positivo para inová-los.

É importante abordar que o modelo de cluster pode ser uma grande contribuição para o desenvolvimento e fortalecimento das micros, pequenas e médias empresas brasileiras, constituindo um mecanismo capaz de solucionar boa parte dos problemas enfrentados por essas organizações.

Temos assim, que o objetivo definido no artigo é plenamente comprovado, uma vez que os cursos superiores de tecnologia atendem às necessidades dos clusters na formação de profissionais com competências específicas, formando capital humano qualificado e contribuindo fortemente para a geração de conhecimento, por meio de produções e pesquisas acadêmicas, sem as quais não haverá possibilidade de formação de docentes e pesquisadores para a educação superior tecnológica.

Finalizando, lembramos que num país com nossas dimensões geográficas e diversidade, certamente, temos regiões com características e competências similares. A educação profissional tecnológica aliada ao ensino a distância (EAD) poderá ser uma forma de fomentar e desenvolver clusters similares ou, ainda, complementares em suas vocações. Porém, é fundamental ter em mente que para o aluno ser bem-sucedido na modalidade de ensino a distância, a autodisciplina é fundamental, para que consiga vencer as etapas do processo de ensinoaprendizagem. O sucesso do ensino a distância (EAD), por ser uma modalidade educativa, não pode desvincular-se do sistema educacional presencial. Assim, em tal contexto, a educação profissional tecnológica representa uma ponte fundamental no processo de ensino-aprendizagem, complementado pelo ensino a distância, e atende aos quatros pilares da educação do século XXI: aprender a conhecer, aprender a fazer, aprender a ser $e$ aprender ao longo da vida. E o contexto da combinação ocasionada por tal fusão de ensino, o local e a necessidade tecnológica necessária ao cluster, remete-nos a uma reflexão futura, mas possível, no que tange à evolução da universidade a que Buarque (2006) chama de pós-universidade:

[...] esta será uma instituição em rede eletrônica, sem endereço, sem nacionalidade, da qual todos poderão participar pelo prazo que lhes for conveniente [...] no ano seguinte o saber já terá sido superado. Não haverá fronteira nítida entre professores e alunos e os dirigentes não poderão exercer um poder hegemônico, sendo também vedada a predominância de uma área sobre outra. 


\section{Referências}

ALTENBURG, T.; MEYER-STAMER, J. How to promote clusters: policy experiences from Latin America. World Development, v.27, n.9, Sept. 1999.

AMATO NETO, J. Redes de cooperação produtiva e clusters regionais. Oportunidades para as pequenas e médias empresas. São Paulo: Atlas, 2000.

BACAL, C. 0 setor de ponta é concentrado e fatura mais. Gazeta Mercantil, São Paulo, pág.A-4, 5 fev. 2001.

BRASIL. Ministério da Educação e Cultura. Lei Federal no 9.394/96. Lei de Diretrizes e Bases da Educação Nacional. Brasilia, DF, 23 dez. 1996. Cap.III, art.39-42.

. Ministério da Educação e Cultura. Lei Federal no 2.208/97. Regulamenta o §2º do art. 36 e art. 39-41 da Lei ํo 9.394, de 17 de abril de 1997. Brasilia, DF.

. Ministério da Educação e Cultura. Parecer CNE/CES no 436. Cursos superiores de tecnologia - formação de tecnólogos. Brasília, DF, 2 abr. 2001.

Ministério da Educação e Cultura. Parecer CNE/CP no -3 . Diretrizes curriculares nacionais para a educação profissional de nível tecnológico. Brasilia, DF, 18 dez. 2002.

. Ministério do Planejamento. Plano Plurianual (2004-2007). Disponivel em: <www.planobrasil.gov.br>.

Ministério da Educação e Cultura. Decreto nํ⒌154. Regulamenta o §2º do art. 36 e art. 39-41 da Lei no 9.394. Brasilia, DF, 23 jul. 2004a.

BUARQUE, C. A pós-universidade. Informativo - Instituto de Estudos Avançados da Universidade de São Paulo, São Paulo, ano 20, p.3, 2006. Disponivel em: <www.iea.usp.br>. Acesso em: 17 maio 2006.

CASTELLS, M. A sociedade em rede. 6. ed. Rio de Janeiro: Paz e Terra, 2002.

FEDERAÇÃO DAS INDÚSTRIAS DO ESTADO DE MINAS GERAIS. Cresce Minas: um projeto brasileiro. Belo Horizonte: Fiemeg, 2000.

FEDERAÇÃO DAS INDÚSTRIAS DO ESTADO DE SÃO PAULO. Ação regional. São Paulo: Fiesp, 2005. Disponível em: <http://www.fiesp.com.br/industria_e_desenvolvimento/secao2/secao3/index.asp?id=2389>. Acesso em: 1 jun. 2005.

GALINARI, R. et. al. 0 efeito das economias de aglomeração sobre os salários industriais: uma aplicação ao caso brasileiro. Belo Horizonte: Cedeplar/Face/UFMG, 2003.

HISSA, H. B. Distritos industriais (ou clusters) como estratégia de desenvolvimento econômico local para o Brasil. Economianet, 2003. Disponível em: <http://www.economiabr.net>. Acesso em: 1 jun. 2005. [É necessário inserir o nome na página]

IEL - INSTITUTO EUVALDO LODI. 0 que é APL? Disponivel em: <http://www.ielpr.org.br/apl/FeeComponent1575contendent6083.shtml>. Acesso em: 31 mar. 2006.

LIMA, J. G. Os tigres brasileiros. Veja, São Paulo, 7 maio 2003. Economia e Negócios, p.102-104.

MANFREDI, S. M. Educação profissional no Brasil. São Paulo: Editora Cortez, 2002.

MORAN, J. M. 0 que é educação a distância Disponivel em: <http://www.eca.usp.br/prof/moran/dist.htm>.Acesso em: 8 ago. 2006.

PIORE, M.; SABEL C. The second industrial divide. New York: Basic Books, 1984.

PORTER, M. E. Vantagem competitiva das nações. Rio de Janeiro: Campus, 1989.

. Clusters and the new economics of competition. Harvard Business Review, Boston, MA, Nov./Dec. 1998.

. Competição. Rio de Janeiro: Campus, 1999.

SACHS, J. Um novo mapa do mundo. Gazeta Mercantil, São Paulo, 30 jun. 1 e 2 jul. 2000. Caderno de Fim de Semana, p.2.

SANTOS, V. M. Notas conceituais sobre a abordagem de clusters produtivos. Espaço Acadêmico, ano III, n.27, ago. 2003.

SEBRAE. Termo de referência para atuação do sistema Sebrae em arranjos produtivos locais. Brasília, DF, jul. 2003. 
SENAC. 0 que é EAD? Disponivel em: <http://www.rj.senac.br/psenac/ead/portalcte/areas/o-que-e-ead.htm>. Acesso em: 5 maio 2006.

SOUZA, C. 0 valor dos clusters - a experiência de Rio Verde deve servir de modelo para o país. Exame, São Paulo, abr. 2003. Caderno Especial Goiás em Exame, p.17-18.

Site consultado

IBGE - Instituto Brasileiro de Geografia e Estatística. Disponivel em: <www.ibge.gov.br>. 